\title{
ANÁLISE ECONÔMICO-FINANCEIRA DO APROVEITAMENTO ENERGÉTICO DO GÁS METANO PROVENIENTE DE INSTALAÇÃO DE SUINOCULTURA
}

\author{
Juciara Oliveira Lopes ${ }^{1}$ \\ Caroline Batista Gonçalves Dias ${ }^{2}$ \\ Rodrigo Nogueira Martins ${ }^{3}$ \\ Nathylla Bianca Costa e Nunes ${ }^{4}$ \\ José Ângeles Moreira de Oliveira ${ }^{5}$ \\ Ailton Rodrigues de Oliveira ${ }^{6}$ \\ Murilo César Osório Camargos ${ }^{7}$
}

Resumo: O presente trabalho objetivou analisar de maneira econômico-financeira o aproveitamento energético do gás metano proveniente das instalações da suinocultura do IFNMG, Campus Januária. Para isso, foram avaliadas duas situações diferentes: o aproveitamento do biogás a partir do biodigestor já instalado e uma segunda situação para analisar desde a instalação do biodigestor ao aproveitamento do biogás. No cenário de 10 anos foram obtidos, na situação 1 payback de 4,46 anos, VPL de R\$38.209,42, e o TIR de 19\%, e na situação 2 payback de 1,10 anos, VPL de $R \$ 82.698,00$ e TIR de 86\%. Representando assim, um investimento atraente para a instituição e possivelmente para produtores rurais no Norte de Minas Gerais, com produção suinícola similares a este estudo.

Palavras-chave: Biogás; Energia alternativa; Dejetos.

\footnotetext{
${ }^{1}$ Engenharia Agrícola e Ambiental/Instituto Federal do Norte de Minas Gerais - IFNMG Campus Januária, Brasil. E-mail: juciaraoliveiralopes@yahoo.com.br.

2 Engenharia Agrícola e Ambiental/Instituto Federal do Norte de Minas Gerais - IFNMG Campus Januária, Brasil. E-mail: caroline.eaa@hotmail.com.

${ }^{3}$ Engenharia Agrícola e Ambiental/Instituto Federal do Norte de Minas Gerais - IFNMG Campus Januária, Brasil. E-mail: rodrigonmartins@hotmail.com.

${ }^{4}$ Engenharia Agrícola e Ambiental/Instituto Federal do Norte de Minas Gerais - IFNMG Campus Januária, Brasil. E-mail: nathylla@yahoo.com.br.

${ }^{5}$ Engenharia Agrícola e Ambiental/Instituto Federal do Norte de Minas Gerais - IFNMG Campus Januária, Brasil. E-mail: j.ngeles@yahoo.com.

${ }^{6}$ Engenharia Agrícola e Ambiental/Instituto Federal do Norte de Minas Gerais - IFNMG Campus Januária, Brasil. E-mail: ailton.r.oliveira@outlook.com

${ }^{7}$ Me Engenharia Agrícola/Instituto Federal do Norte de Minas Gerais - IFNMG Campus Januária, Brasil. E-mail: murilocamargos@gmail.com.
} 